\title{
MODEL DINAMIS PENGELOLAAN USAHA RUMAH POTONG HEWAN-RUMINANSIA
}

\author{
Maya Dewi Dyah Maharani \\ Fakultas Teknik, Universitas Sahid \\ Jl. Soepomo No 84, Jakarta Selatan \\ Email Korespondensi: mayasudarsono@gmail.com
}

\begin{abstract}
ABSTRAK
Pengelolaan usaha jasa Rumah Potong Hewan-Ruminansia (RPH-R) cenderung belum dirancang secara berkelanjutan dari harmonisasi dimensi lingkungan, ekonomi, sosial, peraturan dan teknologi, baru terbatas berkelanjutan secara dimensi ekologi atau ekonomi. Tujuan penelitian ini adalah merumuskan model pengelolaan usaha jasa RPH-R secara berkelanjutan yang dibangun dari lima dimensi, yaitu dimensi lingkungan, ekonomi, sosial, peraturan dan teknologi. Perubahan jumlah ternak yang dipotong mengakibatkan pergeseran keseimbangan komponen jumlah keuntungan usaha jasa RPH-R. Proyeksi jumlah ternak yang dipotong di RPH-R pemerintah perlu diketahui untuk merumuskan besarnya subsidi pemerintah di masa yang akan datang. Permodelan dilakukan dengan menggunakan perangkat lunak POWERSIM 2.5. Simulasi yang dilakukan pada model pengelolaan usaha jasa RPH-R secara berkelanjutan berdasarkan jumlah penggunaan air mewakili dimensi ekologi, jumlah keuntungan yang mewakili dimensi ekonomi, serta berdasarkan teknologi yang dipartisipasikan mewakili dimensi sosial periode 2014-2023. Hasil pemodelan menunjukkan bahwa untuk perubahan penggunaan air pada dimensi ekologi selama periode 2014-2023 adalah menurun, sedangkan untuk jumlah keuntungan pada dimensi ekonomi dan dimensi sosial meningkat.
\end{abstract}

Kata kunci: berkelanjutan, pengelolaan RPH-R, model dinamik

\begin{abstract}
The management of the Livestock-Ruminant (RPH-R) Livestock Service business business tends not to be sustainably designed from the harmonization of environmental, economic, social, regulatory and technological dimensions, only finely sustainable in ecological or economic dimensions. The purpose of this research is to formulate RPH-R service business management model continuously built from five dimensions, namely environmental dimension, economy, social, regulation and technology. Changes in the number of cattle being cut resulted in a shift in the equilibrium component of the amount of RPH-R service business profits. The projected number of livestock cut in the RPH-R government needs to be known to formulate the amount of government subsidy in the future. Modeling is done using POWERSIM 2.5 software. The simulations carried out on the RPH-R service business management model on a sustainable basis based on the amount of water use represent the ecological dimension, the number of advantages representing the economic dimension, and based on the technology represented by the social dimension of the period 2014-2023. The modeling results show that for the change of water use on the ecological dimension during the period 2014-2023 is decreased, while for the amount of profit on the economic dimension and social dimension increases.
\end{abstract}

Keyword: sustainable, RPH-R management, dynamic model 


\section{PENDAHULUAN}

Pemodelan sistem berawal dari bagaimana kita mencoba memahami dunia yang ada. Tidak ada model yang benar dan salah. Model dinilai dari sejauh mana dia dapat berguna. Sehingga langkah pertama dalam pemodelan adalah menentukan tujuan dari pemodelan tersebut. Kegunaan model sebagai alat prediksi terletak pada ketepatan dan ketelitian hasil prediksinya. Model juga dapat dipakai sebagai wahana untuk belajar para pihak yang ingin memahami struktur dan perilaku dari sumberdaya alam. Setelah model dapat diselesaikan, maka selanjutnya dapat dilakukan simulasi dalam menentukan pengaruh suatu komponen terhadap indikator-indikator output atau perilaku yang kita desain. Forrester (1961), mendifinisikan simulasi sebagai penyelesaian atau perhitungan tahap demi tahap dari persamaan matematika yang menggambarkan keadaan sistem untuk mengetahui perubahan yang terjadi pada sistem tersebut sehingga diketahui perilakunya.

Sebagai suatu sistem yang terdiri dari banyak komponen, maka pengelolaan unit usaha jasa RPH-R tidaklah mudah. Pengelolaan unit usaha jasa RPH-R merupakan proses dengan kompleksitas tinggi, multidisiplin, serta multi kewenangan. Sejalan dengan pemikiran tersebut, maka pendekatan yang digunakan dalam penelitian ini adalah pendekatan kesisteman. Menurut Eriyatno (2001), pendekatan sistem memberikan penyelesaian masalah dengan metode dan alat yang mampu mengidentifikasi, menganalisis, menstimulasi, dan membuat rancang bangun sistem dengan komponenkomponen yang saling terkait, yang dirumuskan secara lintas disiplin dan komplementer. Salah satu cara untuk menyelesaikan permasalahan yang kompleks dengan pendekatan sistem adalah menggunakan model sistem dinamis. Sistem dinamis adalah suatu cara berfikir menyeluruh dan terpadu, mampu menyederhanakan persoalan yang rumit tanpa kehilangan hal penting yang menjadi perhatian (Muhammadi et al. 2001). Model simulasi sistem dinamis akan memberikan penyelesaian riil yang kompleks dengan mengkomputasi jalur waktu dari komponen model untuk tujuan tertentu dari input sistem dan parameter model.

Agar berbagai persoalan pengelolaan unit usaha jasa RPH-R dapat diselesaikan dengan cepat, menyeluruh dan dapat dipertanggungjawabkan, maka analisis strategi menggunakan sistem dinamis melalui simulasi model. Tujuan penelitian ini adalah merancang model dinamik, merumuskan nilai indeks keberlanjutan pengelolaan unit usaha jasa RPH-R, serta menyusun alternatif model pengelolaan unit usaha jasa RPH-R secara berkelanjutan dengan menggunakan simulasi model.

\section{METODE PENELITIAN}

\section{Jenis dan Teknik Pengumpulan Data}

Jenis data yang digunakan dalam penelitian ini meliputi data primer dan sekunder. Data primer bersumber dari birokrat, pengelola unit usaha jasa RPH-R (swasta), pengguna jasa RPH-R, serta nara sumber lain yang kompeten. Sumber data ekunder adalah dari data-data BPS, PDAM, Pengelola unit usaha jasa RPH-R di Kota dan Kabupaten Bogor, Kota Surabaya dan Malang. 


\section{Metode Analisis}

\section{Analisis Kebutuhan}

Analisis kebutuhan dilakukan terhadap semua pelaku yang terlibat dalam sistem. Analisis ini dinyatakan dengan kebutuhan stakeholder yang berpengaruh terhadap sistem yang dikaji. Dalam penelitian ini kebutuhan yang dianalisa adalah dari pemerintah, pengelola, pengguna jasa, pedagang daging, pedagang ternak, pemeriksa daging, masyarakat konsumen dan akademisi. Analisa ini meliputi survei, dan pendapat ahli. Analisa kebutuhan stakeholder dapat dilihat pada Tabel 1.

Tabel 1 Analisa Kebutuhan Pemangku Kepentingan Pengelolaan RPH-R

\begin{tabular}{|c|c|c|}
\hline No & Pelaku & Kebutuhan \\
\hline \multirow[t]{4}{*}{1} & Pemerintah & $\begin{array}{l}\text { 1. Pemenuhan tingkat konsumsi daging yang } \\
\text { ASUH }\end{array}$ \\
\hline & & 2. Peningkatan retribusi/bagi hasil \\
\hline & & $\begin{array}{l}\text { 3. Semua ternak tertampung dan dipotong di } \\
\text { RPH-R dengan cara penyembelihan halal }\end{array}$ \\
\hline & & 4. Partisipasi dalam pengelolaan unit usaha jasa \\
\hline \multirow[t]{3}{*}{2} & Pengelola & 5. Keuntungan unit usaha jasa RPH-R \\
\hline & & 6. Kebijakan pemerintah yang adil \\
\hline & & 7. Peraturan /pedoman yang tegas \\
\hline \multirow[t]{3}{*}{3} & Pengguna jasa & 8. Harga ternak potong yang terjangkau \\
\hline & & 9. Kontinuitas ketersediaan ternak potong \\
\hline & & 10. Tarif retribusi/bagi hasil yang sesuai \\
\hline \multirow[t]{2}{*}{4} & Masyarakat konsumen & $\begin{array}{l}\text { 11. Kenyamanan dalam mengkonsumsi pangan } \\
\text { asal ternak }\end{array}$ \\
\hline & & 12. Harga pangan asal ternak yang terjangkau \\
\hline \multirow[t]{3}{*}{5} & Akademisi & 13. Melindungi agar ternak lokal tidak punah \\
\hline & & $\begin{array}{l}\text { 14. Hasil pangan asal ternak yang memenuhi } \\
\text { standar higiene sanitasi }\end{array}$ \\
\hline & & 15. Limbah padat dan cair yang dapat dimanfaatkan \\
\hline \multirow[t]{3}{*}{6} & Pedagang ternak & $\begin{array}{l}\text { 16. Transaksi harga ternak berdasar ukuran yang } \\
\text { jelas bukan taksiran }\end{array}$ \\
\hline & & $\begin{array}{l}\text { 17. Teknologi untuk menghasilkan Penambahan } \\
\text { Berat Bobot Hidup }\end{array}$ \\
\hline & & 18. Harga input budidaya yang terjangkau \\
\hline 7 & Pedagang daging & 19. Harga pangan asal ternak atau daging yang adil \\
\hline
\end{tabular}




\section{Perumusan Masalah}

Pada tahap ini dilakukan perumusan masalah yang timbul karena konflik kepentingan berbagai stakeholder yang terlibat. Terjadinya konflik kepentingan antara para stakeholder merupakan masalah yang membutuhkan solusi agar sistem dapat bekerja secara konstruktif. Perumusan masalah dilakukan dalam rangka mencapai tujuan dengan mengetahui permasalahan-permasalahan yang ada dari masing-masing stakeholder dengan adanya pengaruh dari stakeholder yang lain.

\section{Identifikasi Sistem}

Identifikasi sistem merupakan hubungan antara pernyataan dari kebutuhankebutuhan dengan pernyataan khusus dari masalah yang harus diselesaikan untuk mencukupi kebutuhan-kebutuhan tersebut. Hal ini diinterpretasikan ke dalam diagram input-output dan untuk mengetahui hubungan antar variabel dalam sistem digambarkan dalam diagram causal loop. Causal loop menggambarkan pengaruh positif dan negatif serta yang berpengaruh antar elemen atau variabel. Proses untuk pembuatan model selanjutnya dijelaskan dengan stock flow atau diagram alir. Diagram alir ini digunakan untuk menyusun hubungan kuantitatif antar elemen untuk penyusunan model.

\section{Diagram input-output}

Sesuai dengan ruang lingkup model yang fokus pada simulasi jumlah ternak yang datang, maka hanya komponen yang berpengaruh secara langsung terhadap jumlah ternak tersebut yang akan dipertimbangkan di dalam penyusunan model. Komponen input tak terkontrol berpengaruh terhadap sistem, namun tidak bisa dikendalikan oleh model. Komponen input lingkungan berpengaruh terhadap sistem namun tidak diperhitungkan di dalam perancangan model. Sesuai dengan pemahaman sistem yang telah dilakukan sebelumnya, perancang dapat menentukan output model yang diharapkan. Setelah dilakukan running, model dapat menghasilkan output yang sesuai dengan tujuan. Jika model menghasilkan output yang tidak diinginkan, maka perancang model dapat melakukan tindakan pada komponen input terkendali. Diagram input-output untuk sistem pengelolaan unit usaha jasa RPH-R disajikan pada Gambar 1. Pada Gambar 1 terlihat bahwa input sistem terdiri dari input internal dan eksternal. Komponen yang mempengaruhi kerja sistem adalah:

1. Komponen output yang dikehendaki, yang ditentukan berdasarkan hasil analisa kebutuhan

2. Komponen output yang tidak dikehendaki

3. Komponen input yang terkendali atau terkontrol

4. Komponen input yang tidak terkendali atau tidak terkontrol

5. Komponen input lingkungan (faktor eksternal)

Input lingkungan ini mempengaruhi sistem tetapi tidak dipengaruhi oleh sistem.

6. Komponen kontrol sistem.

Melalui mekanisme pengelolaan unit usaha jasa RPH-R secara berkelanjutan, maka output yang tidak dikehendaki dirubah menjadi input terkontrol yang masuk kedalam sistem pengelolaan unit usaha jasa RPH-R secara berkelanjutan. Pada sistem pengelolaan unit usaha jasa RPH-R secara berkelanjutan, input lingkungan terdiri dari berbagai 
kebijakan pemerintah, dan kondisi sosial budaya. Input internal diperlukan agar sistem bekerja dengan baik.

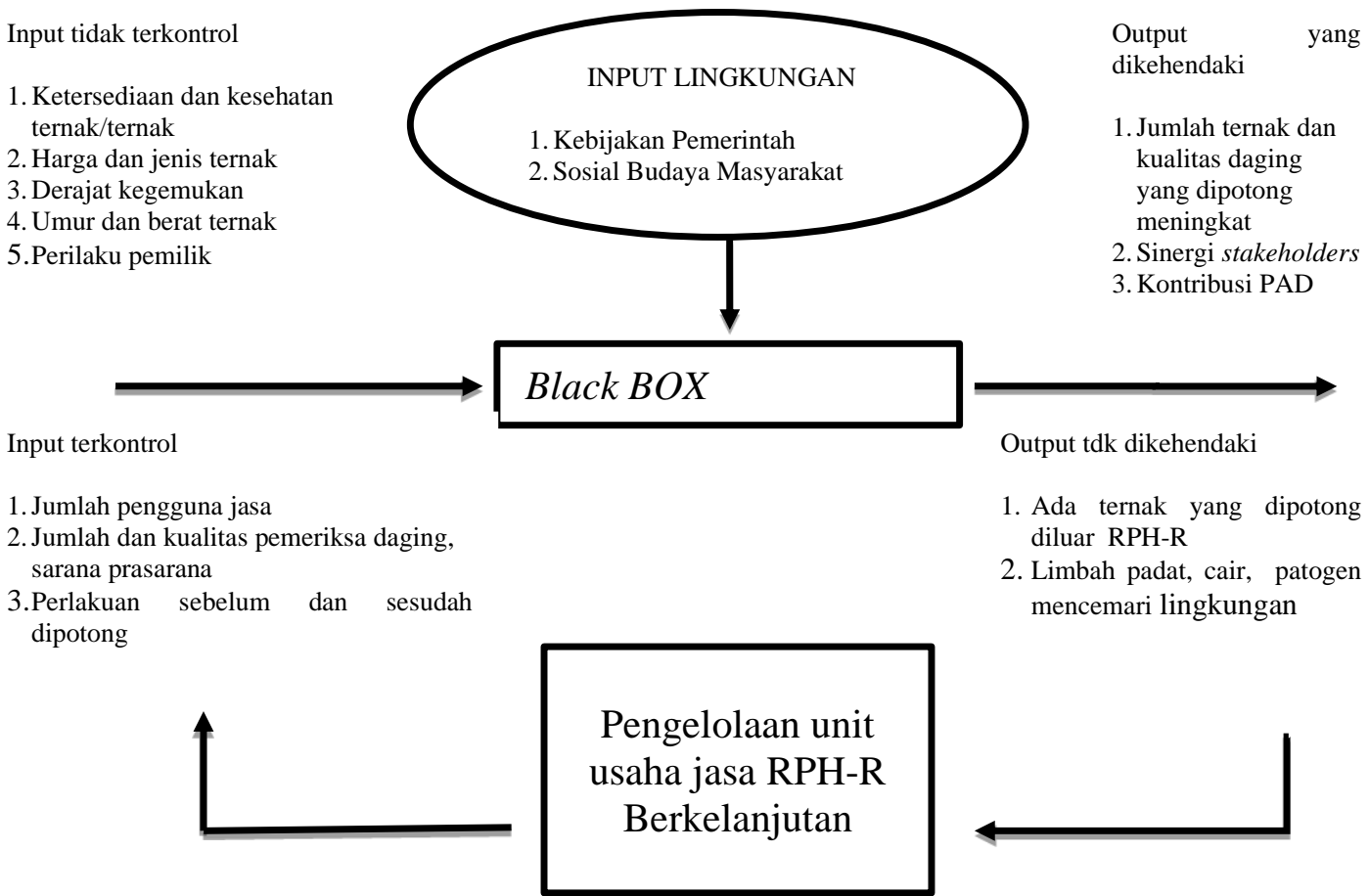

Gambar 1 Diagram Input Output model strategi pengelolaan unit usaha jasa Rumah Potong Hewan-Ruminansia secara berkelanjutan

Input internal terdiri dari dua yaitu input terkendali dan tidak terkendali. Komponen pada input terkontrol merupakan hasil analisis aspek-aspek dalam pembangunan sistem.

\section{Penyusunan Model}

Penyusunan model dinamis keberlanjutan pengelolaan unit usaha jasa RPH-R ini menggunakan beberapa asumsi untuk menyederhanakan dan memudahkan dalam proses analisanya. Simulasi model digunakan untuk membuat skenario pengelolaan unit usaha jasa RPH-R secara berkelanjutan. Simulasi dilakukan untuk jangka waktu enam belas tahun yang akan datang, yaitu dari tahun 2015 sampai 2030. Simulasi dilakukan melalui model tetap dan nilai parameter yang diintervensi. Selanjutnya hasil simulasi terhadap parameter akan ditafsirkan dalam suatu strategi.

HASIL DAN PEMBAHASAN 


\section{Model Dinamik Pengelolaan Unit usaha Jasa RPH-R secara Berkelanjutan}

Pada model ini digambarkan sebab akibat menurun dan meningkatnya keberlanjutan pengelolaan unit usaha jasa RPH-R di masa yang akan datang, melalui harmonisasi dimensi ekologi, ekonomi, sosial, peraturan serta teknologi. Pengelolaan unit usaha jasa RPH-R secara berkelanjutan dapat diujudkan, apabila harmonisasi ke lima dimensi tersebut dipertahankan. Diagram sebab akibat keberlanjutan pengelolaan unit usaha jasa RPH-R menggambarkan sebab akibat menurun dan meningkatnya harmonisasi lima dimensi.

\section{Dimensi Ekonomi}

Keterkaitan komponen jumlah ternak yang akan dipotong dengan keuntungan unit usaha jasa RPH-R membentuk lingkar sebab akibat positif. Selanjutnya besarnya nilai jasa titip, pemotongan, pemeriksaan status kesehatan ternak akan meningkat, jika jumlah ternak yang dipotong bertambah, sebaliknya jika jumlah ternak yang dipotong menurun, maka besarnya nilai jasa titip, pemotongan, dan pemeriksaan status kesehatan ternak, akan menurun. Hal ini membentuk lingkar sebab akibat positif.

\section{Dimensi Sosial}

Terdapat keterkaitan antara dimensi ekonomi dan sosial yang digambarkan dalam diagram sebab akibat jumlah ternak yang dipotong dengan jumlah Nilai Iuran yang membentuk lingkar sebab akibat positif. Jumlah ternak yang dipotong meningkat menyebabkan jumlah Nilai Iuran yang berasal dari para pengguna jasa bertambah, sebaliknya jumlah ternak yang akan dipotong menurun, jika Nilai Iuran tersebut juga berkurang. Komponen Nilai Iuran akan mempengaruhi terhadap teknologi yang dipartisipasikan dalam ujud pemenuhan sarana prasarana RPH-R, antara lain pembangunan prasarana gang way, restraining box, stunning gun, ruang penyembelihan darurat, serta pembangunan prasarana ketersediaan air tanah dangkal. Komponen Nilai Iuran tersebut akan mengurangi beban operasional pengelolaan RPH-R, sehingga akan menambah komponen keuntungan unit usaha jasa RPH-R. 


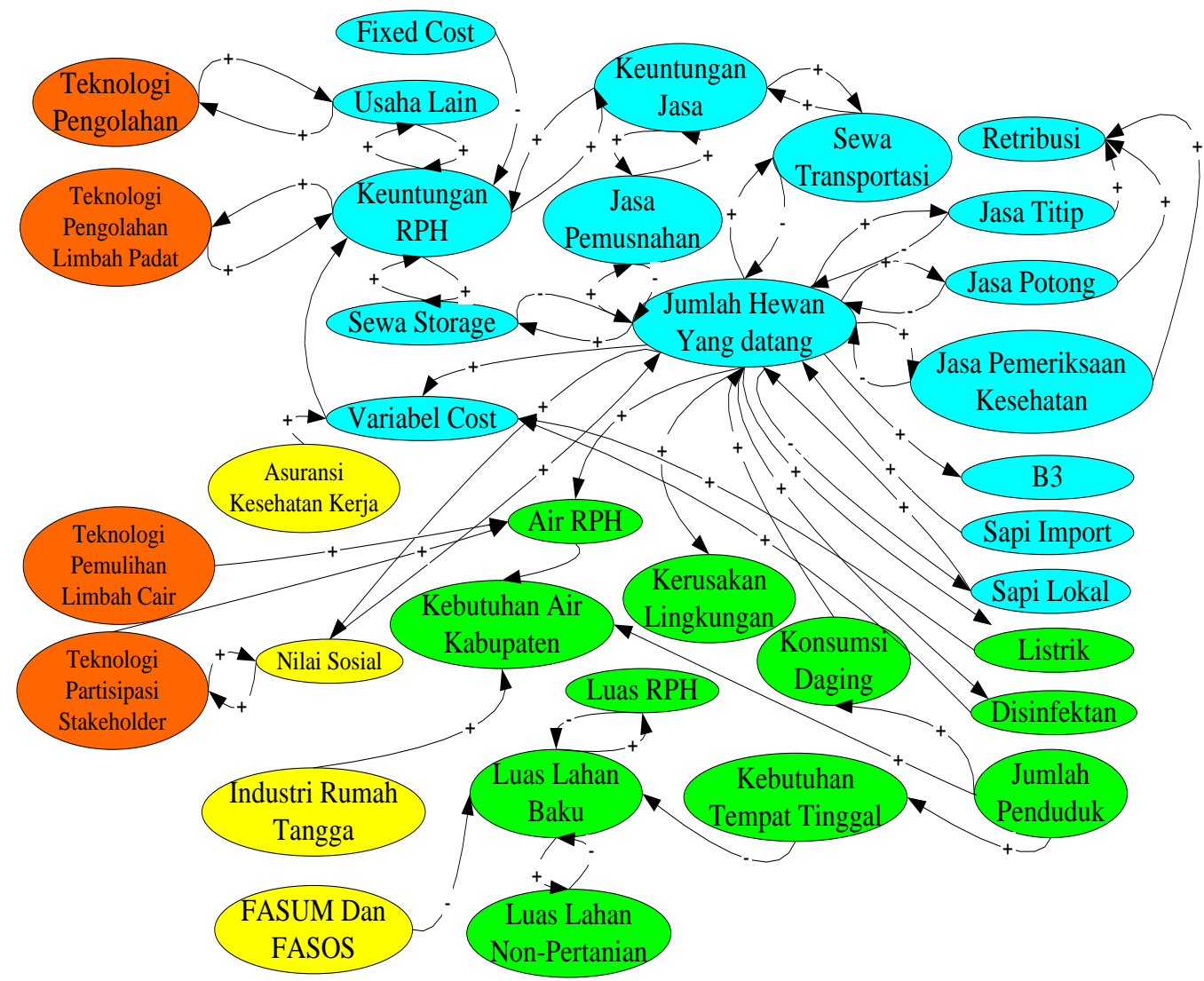

Gambar 2 Diagram Causal Loop lima dimensi dalam pengelolaan unit usaha jasa RPH-R secara berkelanjutan

Upaya memaksimalkan komponen keuntungan unit usaha jasa RPH-R melalui Nilai Iuran pada dimensi sosial tersebut guna menunjang keberlanjutan operasional pengelolaan unit usaha jasa RPH-R.

\section{Dimensi Teknologi}

Dimensi teknologi menggambarkan proses penggunaan teknologi-teknologi melalui pemanfaatan sumber daya yang tersedia di sekeliling RPH-R. Teknologi pemulihan air reverse osmosis dan elektrodialisis, serta teknologi yang dipartisipasikan pada dimensi teknologi akan mempengaruhi penghematan penggunaan air, sehingga menyebabkan variabel cost berkurang dan akhirnya keuntungan unit usaha jasa RPH-R akan meningkat. Pemanfaatan komponen teknologi pengolahan akan menambah komponen unit usaha lain yang akan meningkatkan keuntungan unit usaha jasa RPH-R, demikian juga jika keuntungan unit usaha jasa RPH-R meningkat maka pemanfaatan komponen unit usaha lain dan teknologi pengolahan juga meningkat. Hal ini membentuk diagram lingkar sebab akibat positif.

\section{Dimensi Ekologi}


Dimensi ekologi menggambarkan proses pemanfaatan sumber daya alam baik sumber daya air, lahan dan penggunaan energi yang terjadi sepanjang aktivitas pengelolaan unit usaha jasa RPH-R. Komponen penggunaan air di RPH-R merupakan komponen penting dalam keberlanjutan pengelolaan RPH-R. Komponen penggunaan air dalam dimensi ekologi terkait dengan komponen teknologi yang dipartisipasikan dan teknologi pemulihan air pada dimensi teknologi, terkait dengan komponen Nilai Iuran dalam dimensi sosial, serta terkait dengan komponen variabel cost dalam dimensi ekonomi.

\section{Dimensi peraturan}

Meskipun dimensi peraturan tidak terlihat secara nyata dalam diagram causal loop, namun salah satu komponen peraturan kebutuhan air untuk setiap ekor ternak yang akan dipotong tergambar dalam komponen penggunaan air pada dimensi ekologi. Telah disebutkan di bahasan sebelumnya bahwa komponen penggunaan air terkait dengan komponen-komponen yang berada pada baik dimensi sosial, ekonomi, teknologi serta ekologi.

Komponen larangan pemotongan ternak betina bertanduk berproduksi yang merupakan komponen dalam dimensi peraturan dalam diagram causal loop juga terlihat terkait dengan komponen jumlah ternak yang akan dipotong pada dimensi ekonomi. Sedangkan komponen jumlah ternak yang akan dipotong pada dimensi ekonomi terkait dengan komponen-komponen pada dimensi ekologi, sosial, teknologi. Dengan demikian keterkaitan dimensi peraturan dengan dimensi-dimensi lainnya tergambar dalam diagram causal loop.

Tahapan selanjutnya dari diagram Causal Loop lima dimensi dalam pengelolaan unit usaha jasa RPH-R secara berkelanjutan, diterjemahkan dalam sistem dinamis dengan menggunakan software powersim.

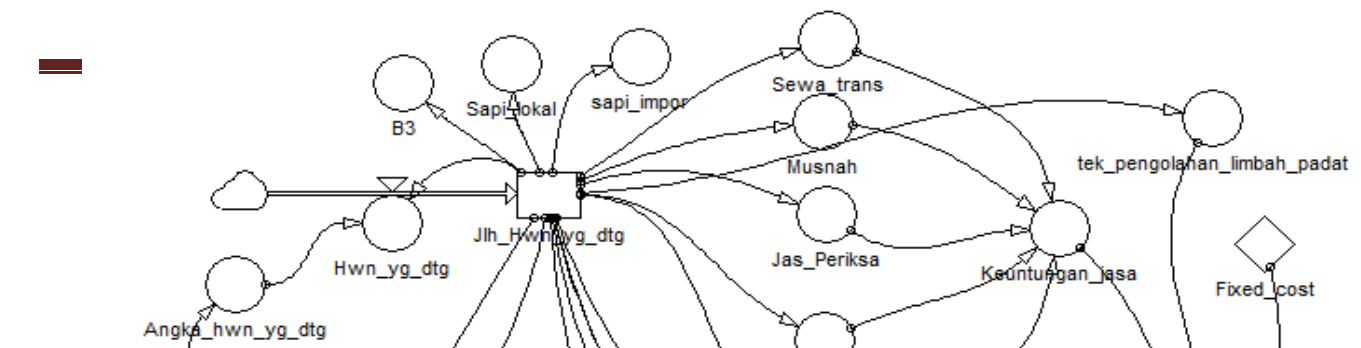


Uji validasi kinerja dapat dilakukan terhadap satu atau lebih komponen yang dominan. Berdasarkan hal tersebut dan ketersediaan data yang ada maka dipilih perkembangan jumlah ternak yang datang, luas lahan RPH-R, Nilai Iuran, luas lahan peruntukan pertanian, pada data aktual, dan simulasi selama sepuluh tahun terakhir (20052014).

Uji validitas menggunakan metode statistik MAPE dilakukan terhadap komponen jumlah ternak yang akan dipotong, luas lahan lokasi RPH-R, Nilai Iuran, luas lahan peruntukan pertanian, jumlah Unit usaha Mikro Kecil Menengah (UMKM), serta penduduk. Hasil uji validasi berdasarkan jumlah ternak yang akan dipotong menunjukkan bahwa MAPE menyimpang sebesar 2,04 \% dari data aktual. Bilangan tersebut masih di dalam batas penyimpangan yaitu kurang dari $10 \%$.

Tabel 1 Data prediksi model pengelolaan unit usaha jasa rumah potong hewan-ruminansia secara berkelanjutan berdasarkan jumlah keuntungan unit usaha jasa RPH-R periode 2014-2030

\begin{tabular}{lllllr}
\hline Th & Retribusi & $\begin{array}{l}\text { Pemasukan } \\
\text { dan Retribusi }\end{array}$ & Pengeluaran & $\begin{array}{l}\text { Keuntunga } \\
\text { n RPH-R }\end{array}$ & $\begin{array}{l}\text { Keuntungan } \\
\text { stlh Subsidi }\end{array}$ \\
\hline 2014 & 811.800 .000 & 11.288 .772 .000 & 10.401 .406 .571 & 75.565 .429 & 875.565 .429 \\
2015 & 811.808 .118 & 11.288 .884 .888 & 10.392 .990 .317 & 84.086 .454 & 884.086 .453 \\
2016 & 811.816 .236 & 11.288 .997 .777 & 10.384 .052 .167 & 93.129 .375 & 893.129 .374 \\
2017 & 811.824 .354 & 11.289 .110 .667 & 10.374 .510 .096 & 102.726 .218 & 902.776 .217 \\
2018 & 811.832 .473 & 11.289 .223 .560 & 10.364 .480 .114 & 112.910 .973 & 912.910 .973 \\
2019 & 811.840 .591 & 11.289 .336 .452 & 10.353 .776 .145 & 123.719 .717 & 923.719 .716 \\
2020 & 811.848 .709 & 11.289 .449 .345 & 10.342 .409 .897 & 135.190 .740 & 935.190 .739 \\
2021 & 811.856 .828 & 11.289 .562 .240 & 10.330 .340 .732 & 147.364 .682 & 947.364 .680 \\
2022 & 811.864 .947 & 11.289 .675 .137 & 10.317 .525 .515 & 160.284 .676 & 960.284 .675 \\
2023 & 811.873 .065 & 11.289 .788 .034 & 10.303 .918 .467 & 173.996 .563 & 973.996 .502 \\
2024 & 811.881 .184 & 11.289 .900 .933 & 10.289 .470 .997 & 188.548 .752 & 988.548 .752 \\
2025 & 811.889 .303 & 11.290 .013 .832 & 10.274 .131 .534 & 203.992 .995 & 1.003 .992 .995 \\
2026 & 811.897 .422 & 11.290 .126 .732 & 10.240 .554 .329 & 237.674 .981 & 1.037 .674 .981 \\
2027 & 811.905 .541 & 11.290 .239 .634 & 10.222 .196 .832 & 256.137 .261 & 1.056 .137 .261 \\
2028 & 811.913 .660 & 11.290 .352 .537$. & 10.202 .707 .409 & 275.731 .468 & 1.075 .731 .468 \\
2029 & 811.921 .779 & 11.290 .465 .441 & 10.182 .016 .601 & 296.527 .061 & 1.096 .527 .061 \\
\hline 2030 & 811.929 .898 & 11.290 .578 .346 & 10.160 .050 .687 & 318.597 .761 & 1.118 .597 .761
\end{tabular}

Tabel 1 memperlihatkan bahwa pemasukan unit usaha jasa RPH-R meningkat, disebabkan oleh meningkatnya komponen keuntungan unit usaha jasa RPH-R dan retribusi yang dihasilkan. Komponen keuntungan unit usaha jasa dan retribusi meningkat disebabkan oleh beberapa komponen yang berkaitan serta berpengaruh terhadap meningkatnya pemasukan unit usaha jasa RPH-R tersebut adalah: (1) jumlah ternak yang dipotong, (2) retribusi, (3) pemanfaatan teknologi pemulihan atau recovery air; (4) pemanfaatan teknologi yang dipartisipasikan oleh pengguna jasa dalam bentuk pembuatan prasarana pemanfaatan sumur air tanah dangkal.

\section{KESIMPULAN}

Pengelolaan unit usaha jasa pemotongan yang saat ini dilakukan oleh RPH-R pemerintah adalah sebagai berikut: 
1. Pengelola melakukan manajemen RPH-R tidak mempertimbangkan risiko berkurangnya ketersediaan air di sekitar lokasi

2. Upaya mendapatkan keuntungan maksimal dari unit usaha jasa RPH-R sulit dilaksanakan, meskipun sudah ditempuh melalui unit usaha lain dalam bentuk pengolahan hasil daging atau pangan asal ternak.

Perbaikan pengelolaan unit usaha jasa RPH-R agar dapat operasional berkelanjutan dapat ditempuh melalui:

1. Pengelolaan risiko terhadap status kesehatan ternak

2. Memaksimalkan keuntungan melalui unit usaha lain, dalam hal ini pengolahan pangan asal ternak (daging) menjadi produk olahan

3. Melakukan pemulihan terhadap sumber daya alam seperti penggunaan teknologi reverse osmosis dan elektrodialisis untuk memulihkan air, sehingga penggunaan air dapat dihemat.

\section{DAFTAR PUSTAKA}

Aminullah, M \& Soesilo, B. E. (2001). Analisa Sistem Dinamis: Lingkungan Hidup, Sosial, Ekonomi, Manajemen. UMJ Press. Jakarta.

Eriyatno., (2012). Ilmu sistem meningkatkan mutu dan efektivitas manajemen. 1(4): $134: 138$

Forrester, J.W. (1961). Industrial Dynamics. Portland (OR): Productivity Press. 